\title{
Subacute sensory neuronopathy and cancer: the identification of paraneoplastic syndromes
}

\author{
Matthew C Kiernan, ${ }^{1,2}$ David R Cornblath ${ }^{3}$
}

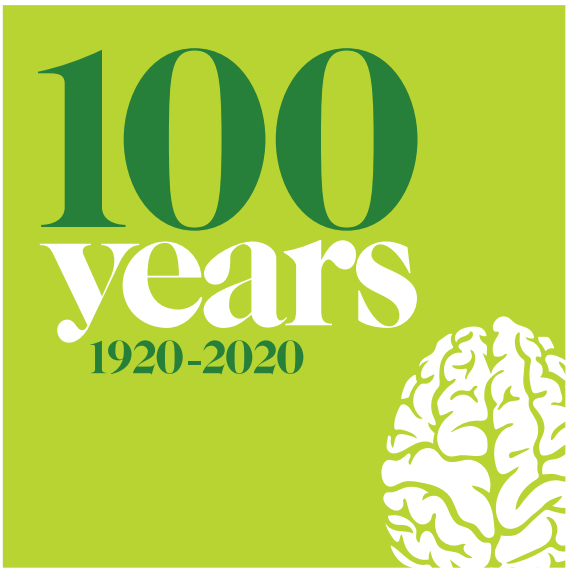

In this landmark paper, Denny-Brown published cases of severe sensory ataxia found at autopsy to have sensory ganglionopathy in association with bronchogenic carcinoma

The concept of paraneoplastic disorders is relatively recent in the clinical neurosciences, and one that remains incompletely understood to this day, particularly in terms of therapy. By means of definition, paraneoplastic disorders have tended to encompass all remote effects of cancer, not attributable to metastases, treatment or the presence of coexistent illness. ${ }^{1}$ In terms of disease pathophysiology, the cause of paraneoplastic disorders has been linked to a form of immunological cross-reactivity between tumour antigens and neuronal tissue, thereby triggering an immune-based attack on the nervous system.

Early concepts of paraneoplastic phenomenon slowly emerged through the study of neuropathy. Until 60 years ago, the literature on neuropathy itself was relatively sparse. Most neuropathies were

\footnotetext{
'Bushell Chair of Neurology, Brain and Mind Centre, University of Sydney, Sydney, New South Wales, Australia

${ }^{2}$ Neurology, Royal Prince Alfred Hospital, Camperdown, New South Wales, Australia

${ }^{3}$ Department of Neurology, Johns Hopkins University, Baltimore, Maryland, USA

Correspondence to Professor Matthew C Kiernan, Bushell Chair of Neurology, Brain and Mind Centre, University of Sydney, Sydney, Australia; matthew. kiernan@sydney.edu.au
}

Primary sensory neuropathy with muscular changes associated with carcinoma

Authors: Denny-Brown D

Year published: 1948

Number of times cited: 475

described as sensory and motor, starting distally with proximal progression. As Lecturer Dr Derek Ernest Denny-Brown (then later Professor, OBE, MD, FRCP) pointed out in this landmark JNNP paper, sensory neuropathies were generally considered rare and were usually attributed to infection such as tabes or a postinfectious process like Guillain-Barré syndrome. ${ }^{2}$ Denny-Brown's paper that launched a concept for paraneoplastic phenomena began by describing two cases (one a boiler cleaner and the other a retired Army Colonel) $n$ which both had initially presented with rapidly progressive, painful, sensory ataxic syndromes. ${ }^{2}$ On neurological examination, both patients displayed ataxia, severely reduced sensation and reduced or absent reflexes. Both died within 8 months. Subsequent autopsy identified a severe loss of dorsal root ganglion cells as the cause of neuropathy and the unexpected presence of bronchogenic pulmonary carcinoma. Specifically, Denny-Brown described the severe loss of nerve cells in the dorsal root ganglia without corresponding change in the ventral roots and concluded that the similarity of clinical phenotype in these two patients suggested that the presence of carcinoma was more than just a chance occurrence.

Possible causes of the neuropathic symptoms raised at the time of the DennyBrown study included tumour invasion into the lymphatics of the peripheral nerves and invasion into intrathecal portions of the spinal nerves, in addition to potential toxic and metabolic pathways. ${ }^{2}$ Denny-Brown ended by suggesting that the cause of the neuropathy was likely 'the result of a nervous reflex from the lung'. He further surmised that the cancer may have triggered a metabolic disorder and likened the presentations to vitamin deficiencies, akin to animals afflicted with vitamin $\mathrm{E}$ deficiency.

The description of a connection between neuropathy and a coexistent carcinoma has in turn linked DennyBrown to the syndrome of sensory ganglionopathy associated with cancer. Subsequent studies have more precisely identified the cause of this specific syndrome to circulating auto-antibodies (anti-Hu) directed against intracellular antigens present in the dorsal root ganglion cells. ${ }^{3}$ Further clinical research has greatly expanded our understanding of these paraneoplastic syndromes more generally, with the unifying feature linked to an immune-mediated pathogenesis. ${ }^{4}$ Distinct antigens have led to classifications based around clinical phenotypes and associated autoantibody production and also through the location of the antigen, being either intracellular or extracellular. ${ }^{56}$ In addition, there can be overlap with similar syndromes which may develop in the absence of an identifiable cancer. In those syndromes with autoantibodies that target intracellular antigens, cancer is almost always present.

While there has been improved understanding in disease pathophysiology, treatment approaches still often remain uncertain. Some disorders such as the Lambert-Eaton myasthenic syndrome and myasthenia gravis may respond well to immunosuppression and to treatment of the underlying tumour. In contrast, encephalomyelitis associated with cancer and paraneoplastic cerebellar degeneration usually respond poorly to treatment. Differences in cellular and humoral immunity, as well as the nature of autoantibody target antigens such as receptors and ion channels, likely underlie these differential responses to therapy. ${ }^{7}$ While the field of paraneoplastic neurology has certainly advanced since the original JNNP landmark study, as Denny-Brown wisely concluded then, more studies on similar cases in the future are indicated to better unlock the precision therapies that will no doubt be required. ${ }^{2}$

Twitter Matthew C Kiernan @jnnp_bmj 
Funding The authors have not declared a specific grant for this research from any funding agency in the public, commercial or not-for-profit sectors.

Competing interests None declared.

Patient consent for publication Not required.

Provenance and peer review Commissioned; internally peer reviewed.

(c) Author(s) (or their employer(s)) 2020. No commercial re-use. See rights and permissions. Published by BMJ.

D) Check for updates

To cite Kiernan MC, Cornblath DR. J Neurol Neurosurg Psychiatry 2020;91:793-794.
Received 6 March 2020

Accepted 11 March 2020

Published Online First 3 April 2020

J Neurol Neurosurg Psychiatry 2020;91:793-794.

doi:10.1136/jnnp-2020-323171

\section{REFERENCES}

1 Ma GMY, Chow JS, Taylor GA. Review of paraneoplastic syndromes in children. Pediatr Radiol 2019;49:534-50.10.1007/s00247-019-04371-y

2 Denny-Brown D. Primary sensory neuropathy with muscular changes associated with carcinoma. J Neurol Neurosurg Psychiatry 1948;11:73-87.

3 Graus F, Cordon-Cardo C, Posner JB. Neuronal antinuclear antibody in sensory neuronopathy from lung cancer. Neurology 1985;35:538-43.
4 Maverakis E, Goodarzi H, Wehrli LN, et al. The etiology of paraneoplastic autoimmunity. Clin Rev Allergy Immunol 2012;42:135-44.

5 Tada S, Furuta M, Fukada K, et al. Severe Parkinsonism associated with anti-CRMP5 antibody-positive paraneoplastic neurological syndrome and abnormal signal intensity in the bilateral basal ganglia. J Neurol Neurosurg Psychiatry 2016:87:907-10.

6 Jitprapaikulsan J, Klein CJ, Pittock SJ, et al. Phenotypic presentations of paraneoplastic neuropathies associated with MAP1B-IgG. J Neurol Neurosurg Psychiatry 2020:91:328-30.

7 Berzero G, Karantoni E, Dehais C, et al. Early intravenous immunoglobulin treatment in paraneoplastic neurological syndromes with onconeural antibodies. J Neurol Neurosurg Psychiatry 2018;89:789-92. 